\title{
Towel Uterus Model for Uterine Compression Sutures Technical Skills Training: A Review of Literature and Development of a Performance Rubric
}

\author{
Milena Garofalo $^{1}$, Glenn D. Posner ${ }^{2}$ \\ 1. Department of Obstetrics and Gynaecology, Faculty of Medicine, Mcgill University, Montreal, Qc, Canada, McGill \\ University Health Centre 2. Department of Innovation in Medical Education, University of Ottawa
}

Corresponding author: Milena Garofalo, milena.garofalo@mail.mcgill.ca

\begin{abstract}
Postpartum hemorrhage ( $\mathrm{PPH}$ ) continues to be the leading cause of maternal mortality worldwide, occurring in about five percent of deliveries. The most common cause of PPH is uterine atony, and a number of medical and surgical management techniques are available to prevent morbidity and mortality associated with PPH in this context. Uterine compression sutures provide a more conservative surgical approach, allowing for the preservation of fertility. Obstetrics and Gynecology (Ob/Gyn) residents need to be adequately trained to competently perform this technique.
\end{abstract}

The goal of this surgical skills training is for $\mathrm{Ob} / \mathrm{Gyn}$ residents to be able to surgically manage PPH using uterine compression sutures. A uterine towel model for surgical skills training in the use of uterine compression sutures was developed. The simulator is explained and compared to similar models. Possible ways to implement and use the simulator in a simulation curriculum are also described. A performancebased assessment rubric was also developed in order to formatively aid with the learning and understanding of the technique. Much work is still needed to test the validity and reliability of this tool, but based on current literature, results may be promising.

Received 03/19/2018 Review began 04/13/2018 Review ended 05/19/2018 Published 06/01/2018

๑) Copyright 2018 Garofalo et al. This is an open access article distributed under the terms of the Creative Commons Attribution License CC-BY 3.0., which permits unrestricted use, distribution, and reproduction in any medium, provided the original author and source are credited.
Categories: Medical Education, Medical Simulation, Obstetrics/Gynecology

Keywords: simulator, uterine compression sutures, obstetrics, medical education, simulation-based assessment

\section{Introduction And Background}

\section{The problem and need}

Postpartum hemorrhage ( $\mathrm{PPH}$ ) continues to be the leading cause of maternal mortality worldwide, occurring in about five percent of deliveries. An estimated 140,000 women die each year secondary to PPH. It is a preventable medical emergency that requires a timely response. The most common cause of PPH is uterine atony, i.e., the inability of the uterine musculature to adequately contract, thus leading to excess blood loss. Most cases of PPH secondary to uterine atony are managed successfully with medical treatment, such as oxytocin or misoprostol. However, occasionally after a vaginal delivery, and more frequently during a cesarean delivery, a surgical approach may be needed. Surgical management of PPH includes balloon tamponade, uterine artery embolization (by interventional radiology), internal iliac or uterine artery ligation, uterine compression sutures, and ultimately hysterectomy [1-2]. Technical skills are required in order to perform these surgical procedures; and as they are relatively rare, Obstetrics and Gynecology (Ob/Gyn) residents, both senior and junior alike, are rarely exposed to them. When they are exposed, the patient is usually unstable and has already had a large amount of blood loss; thus, it is dangerous and unsafe for the patient in question to have someone inexperienced practice on them. The Royal College "Objectives of Training" for Ob/Gyn state that extensive knowledge is required for the "etiology and management, medical and surgical, of early and delayed postpartum hemorrhage" and that a fully trained resident must be competent to perform independently both "nonsurgical and surgical management of moderate and severe postpartum hemorrhage.” This includes the use of uterine compression sutures [3]. This novel simulator described here focuses on the technical skills required to perform the three most common uterine compression sutures, namely the B-Lynch, Hayman, and Cho sutures.

The idea of uterine compression sutures was first introduced by Christopher B. Lynch in 1997 [4]. Since then, various compression sutures, named after their inventors, have been described in observational studies and case series. No higher-level evidence has demonstrated whether compression sutures are better and safer for achieving hemostasis in PPH than other methods, or whether one suture type is better or safer than the other. Other compression sutures include the Cho suture described in 2000 and the Hayman suture (also called modified B-Lynch) described in 2002 [5-6] (see Figures 1-3 for illustrations of these three suture types). They have the advantage of not only being potentially life-saving, but they all also allow for preservation of the uterus and fertility. In the past nine years, there have been several reviews published on 


\section{Cureus}

the subject comparing the different uterine compression sutures [7-10]. A 2007 systematic review reported a 91.7\% success rate for various compression sutures [7]. Most published data discuss the original B-Lynch suture, whose success rate is considered to be $99.5 \%$, based on personal communication with Dr. B. Lynch [10]. There appears to be a substantially decreased success rate, $75 \%$, with a delay of two to six hours following the delivery [8]. Compared to the other types, the B-Lynch suture has the advantage that it does not sew the anterior and posterior uterine walls together, thus potentially decreasing the risk of pyometra and synechiae. These two complications have been reported with the Cho suture [10]. The Hayman technique is a simple modification of the B-Lynch, which does not require the opening of the uterine cavity (hysterotomy). It is thus simpler and quicker. For all of these techniques, data on future fertility are scarce [9].

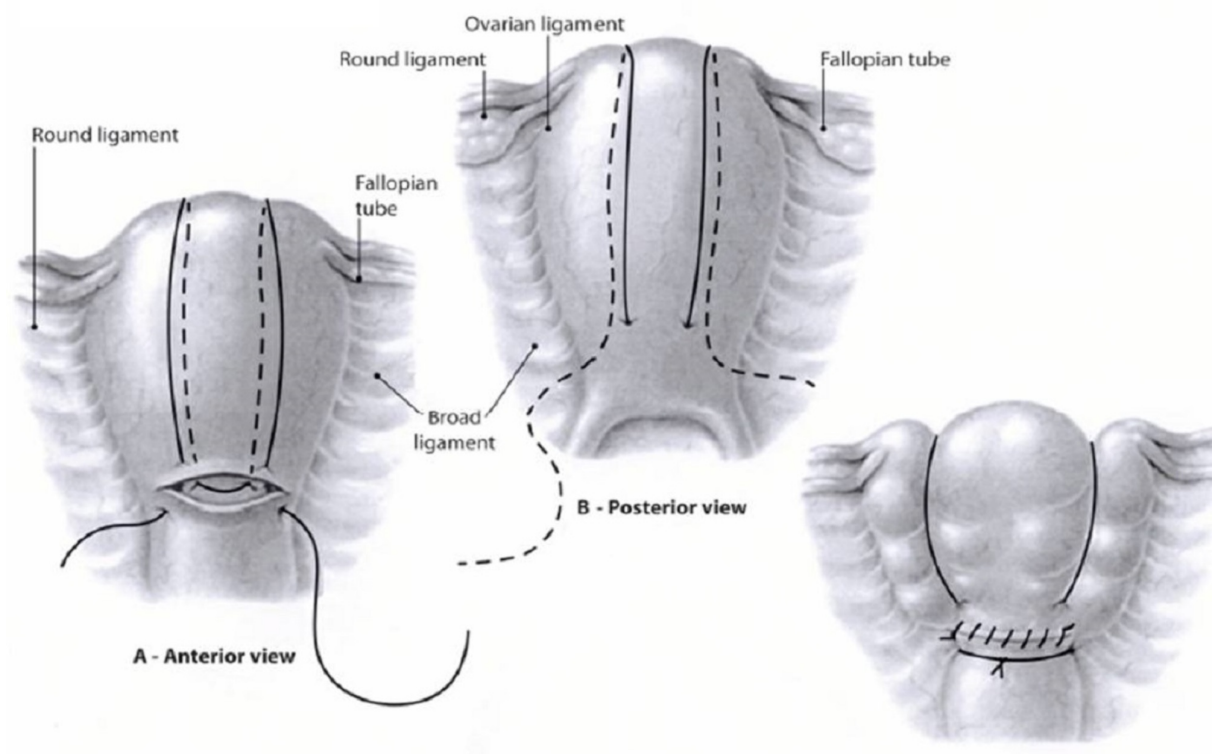

C-Anterior view

\section{FIGURE 1: B-Lynch compression suture}

\section{[2].}
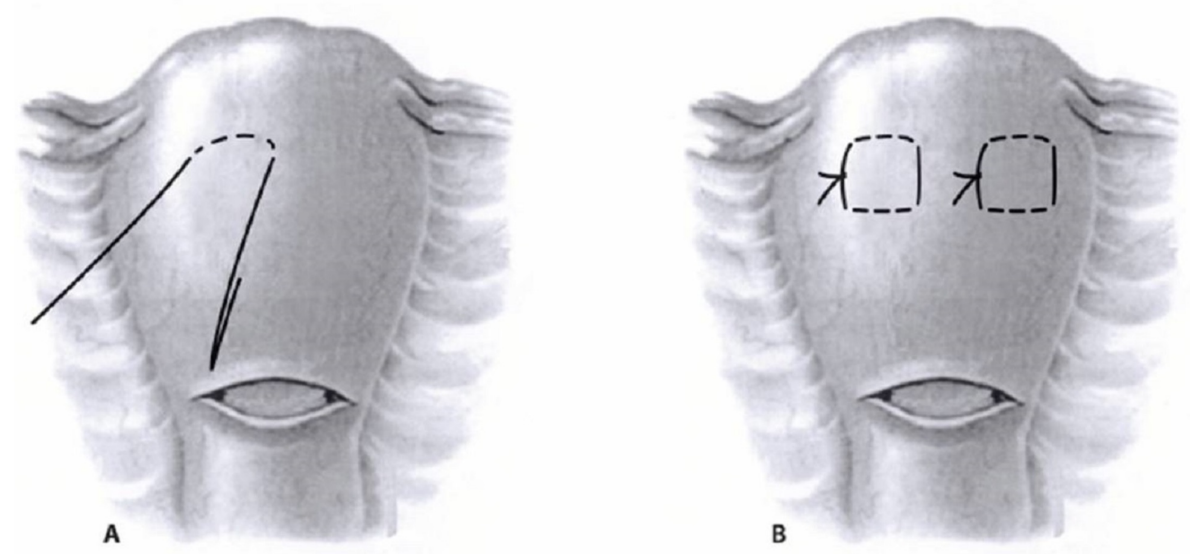

FIGURE 2: Cho compression suture

[2]. 


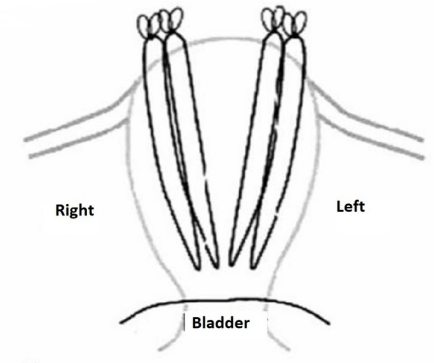

A

FIGURE 3: Hayman compression suture

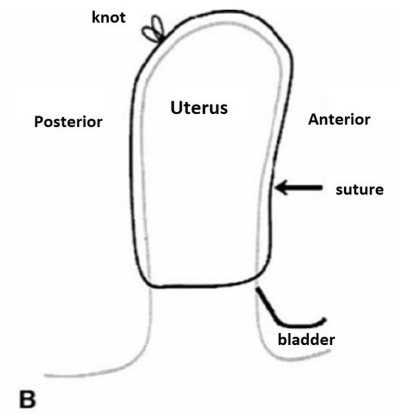

[6].

\section{Review}

\section{Uterine compression sutures technical skills training}

Goals and Objectives: The goal of this surgical skills training is for Ob/Gyn residents to be able to surgically manage PPH with the use of uterine compression sutures. There are six main objectives to the training which are included in the more detailed performance rubric at the end of the paper and which form the criteria of the assessment tool. At the end of the session, the resident should be able to:

1. Recognize when surgical management of PPH is needed.

2. Know the different options for surgical management of PPH, including the relevant anatomy.

3. Describe and compare B-Lynch, Hayman, and Cho uterine compression sutures.

4. Select the appropriate suture/needle material and instruments for the compression suture.

5. Demonstrate B-Lynch, Hayman, and Cho uterine compression sutures on a towel uterine model (the simulator).

6. Perform the compression sutures in a timely and efficient manner.

\section{Educational tool: the simulator}

The task trainer/simulator developed and described for this project is shown in Figure 4. It was made using a medium-sized red towel, folded in such a way so as to simulate the hysterotomy (lower transverse uterine incision), with the two ends of the towel. Red tape was used to create the shape of the uterus and to hold the model together. In order to increase the realism of the model, the uterine vessels, fallopian tubes, ovaries, and broad ligament may also be included as in the models in Figures 5, 7, 9. This model is feasible due to its low cost (approximately CAD 5 per model), and just like the other similar models described below, it has both instrumental and procedural fidelity. This is because the same instruments, materials, and procedural steps as used in real-life can be replicated with the simulator possibly leading to the transfer of skills to the real world. It does not provide tissue or physiologic fidelity. Anatomic fidelity may be increased by adding the uterine arteries, fallopian tubes, and ovaries.

A review of literature yielded similar uterine models to the one discussed above: a knitted wool model (see Figure 5), a women's pantyhose stocking filled with cotton wool/fiber fill (see Figure 6), a model made using two face cloths (See Figure 7), and finally a model using a hot water bottle mounted on a wooden board (Figure 8). They all have been described as low-cost learning tools to train students on using uterine compression sutures [11-14]. None specifically discuss the reliability and validity of the simulator itself. Only one of these models (the hot water bottle) was used as part of an assessment tool, and thus had some performance metrics outlined in the form of a global rating scale (GRS) and task-specific checklist [14]. Both will be detailed in the next section. 


\section{Cureus}

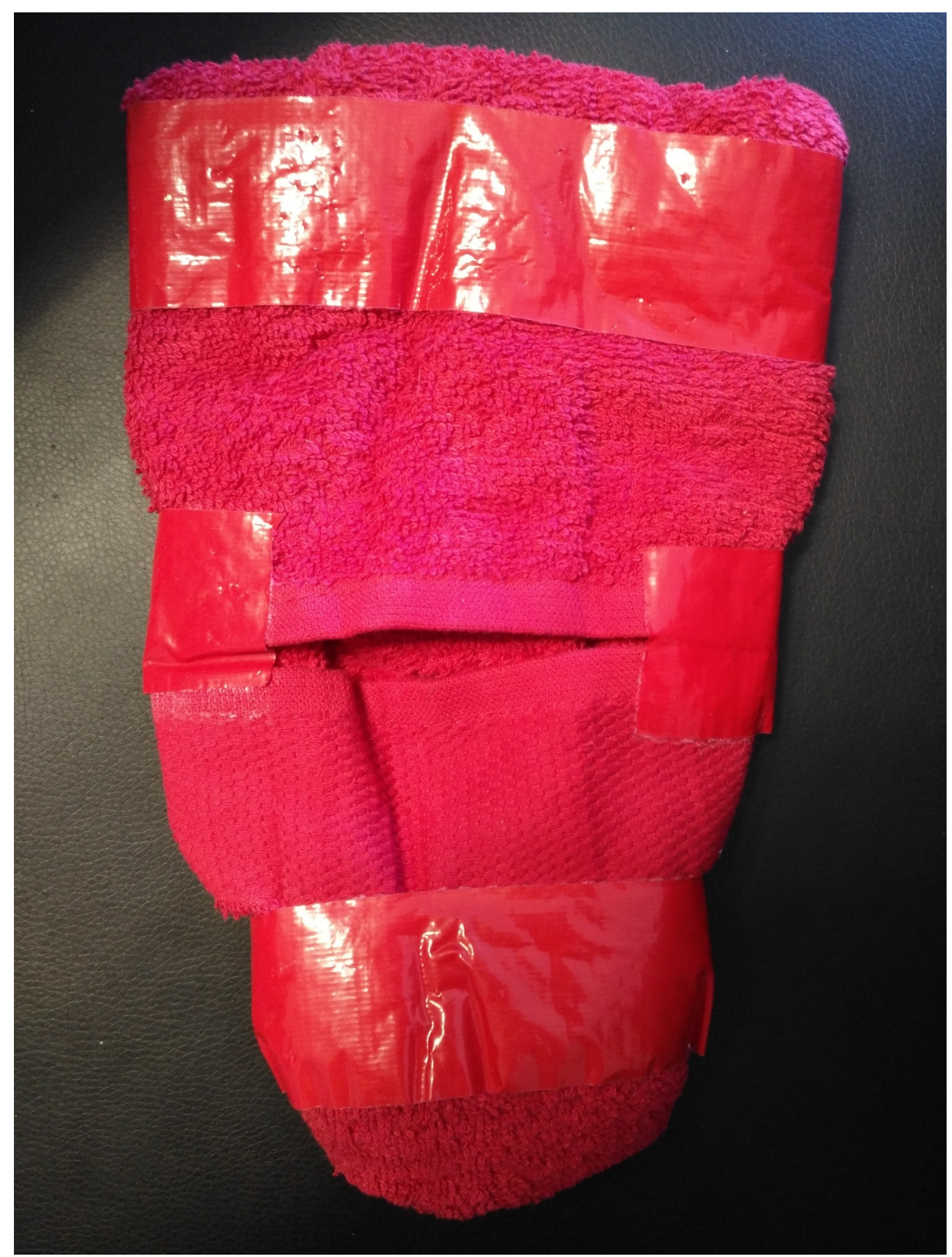

FIGURE 4: Uterine towel model - our simulator 


\section{Cureus}
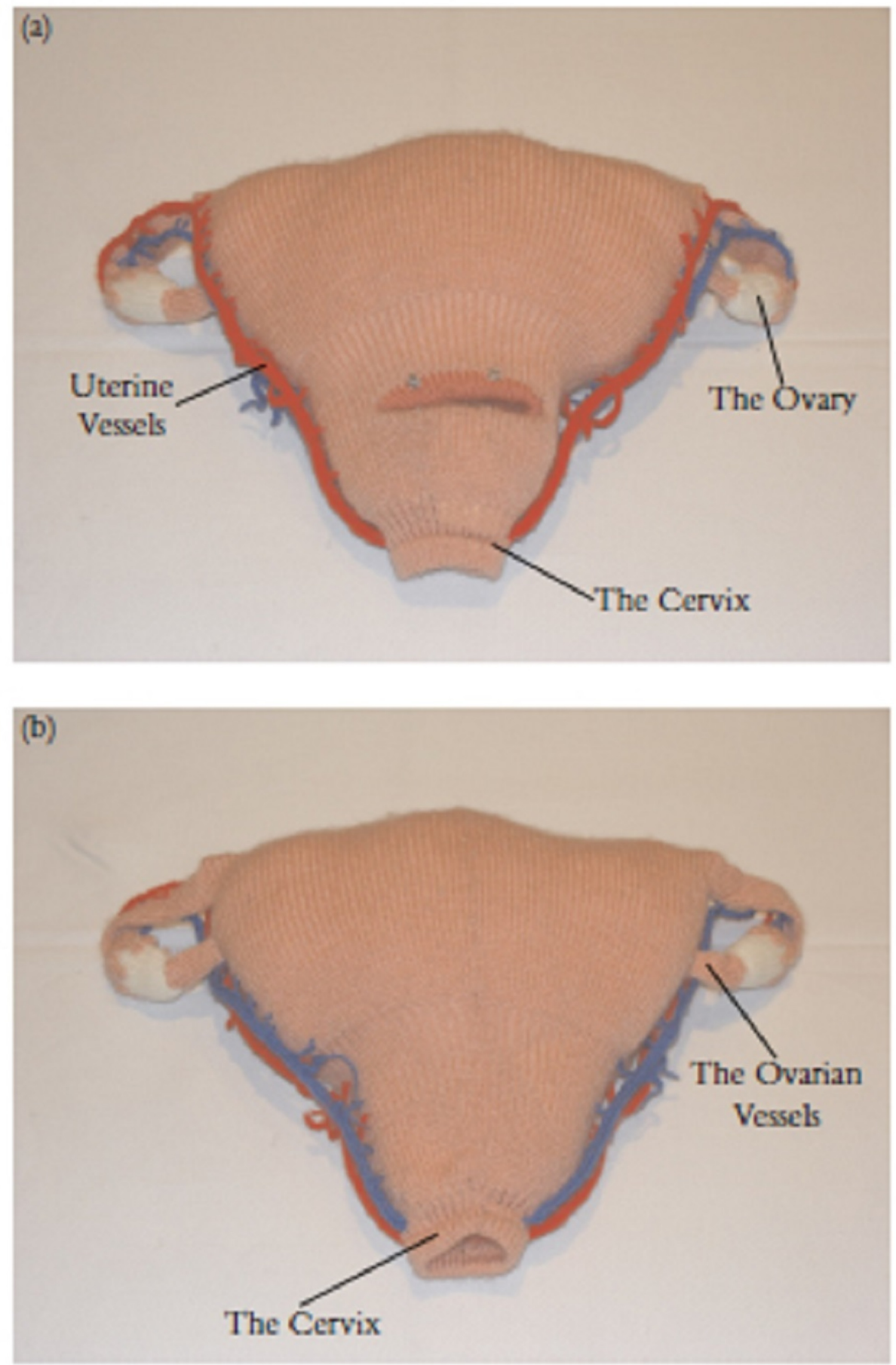

FIGURE 5: Knitted wool model

[11]. 


\section{Cureus}

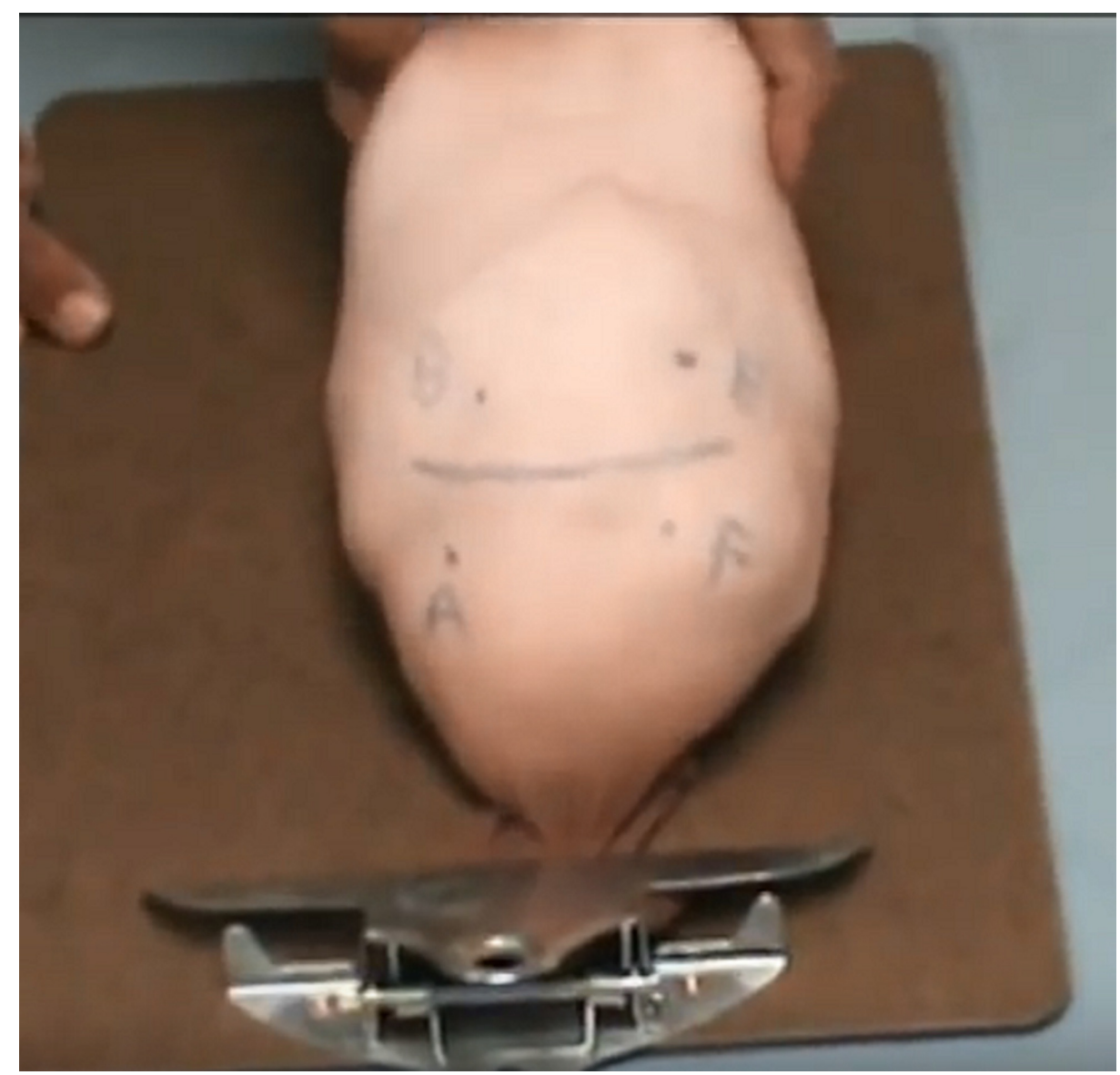

FIGURE 6: Filled pantyhose stocking model

[12].

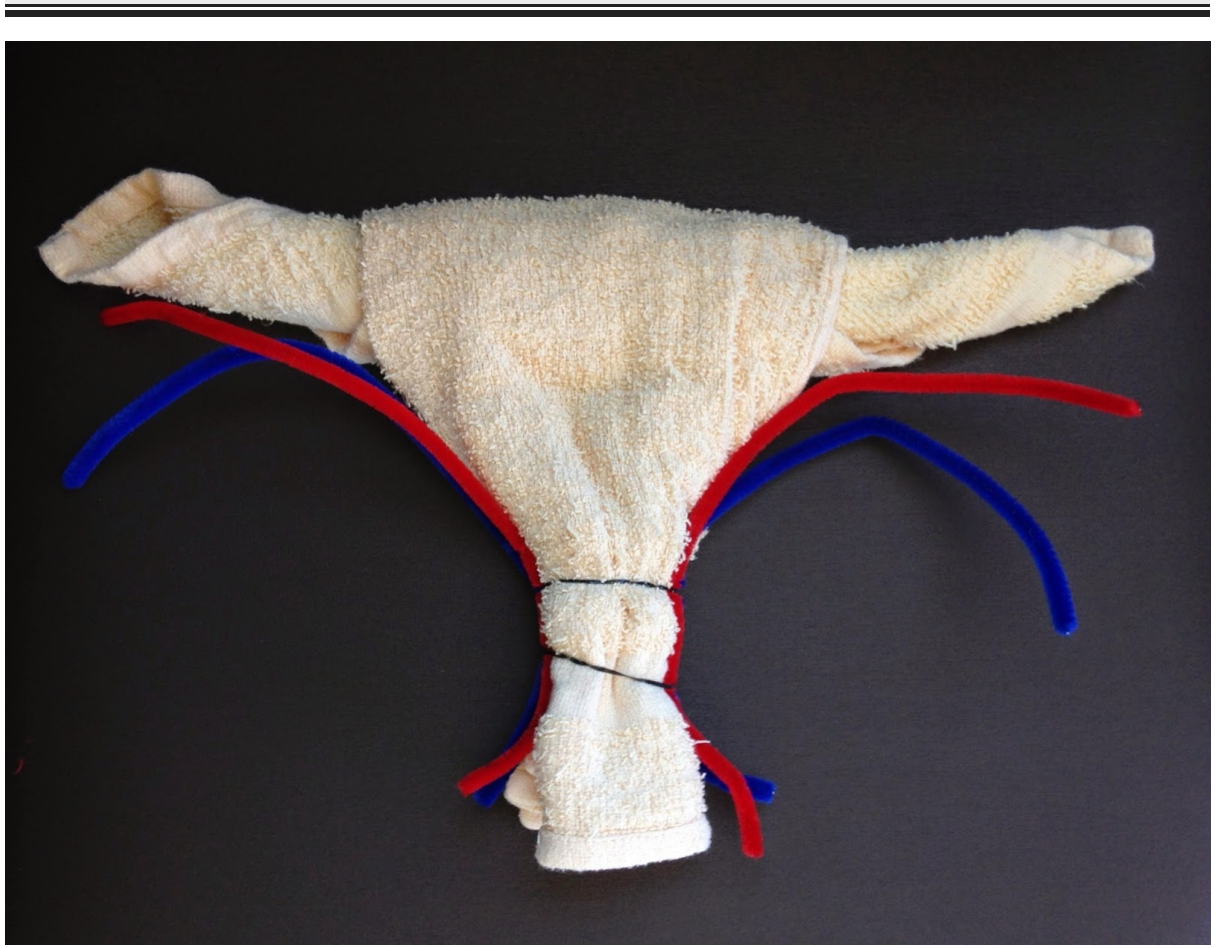

FIGURE 7: Face cloth model

[13]. 


\section{Cureus}

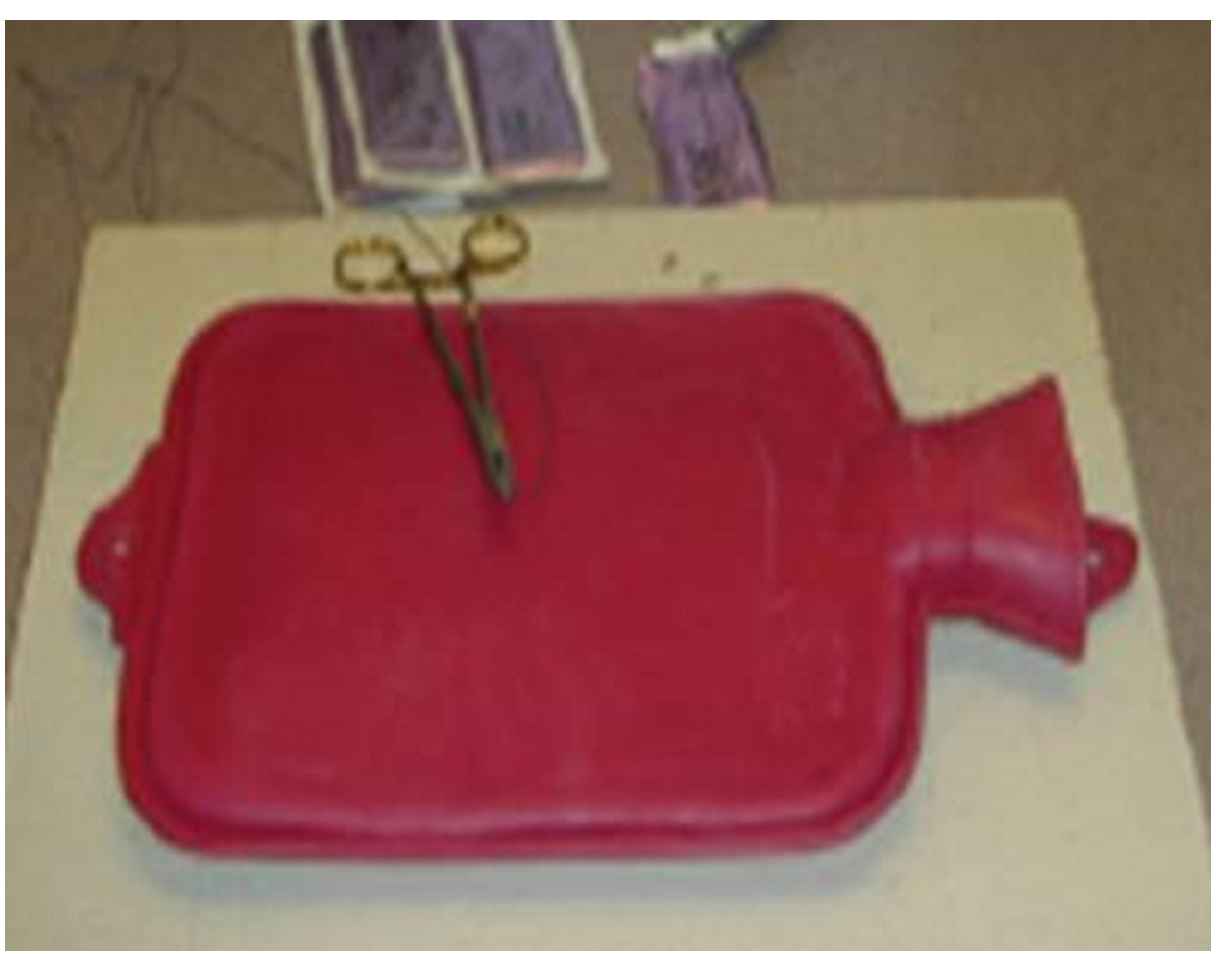

FIGURE 8: Hot water bottle model

[14].

\section{Implementation}

Postpartum hemorrhage is an obstetrical emergency, and every $\mathrm{Ob} / \mathrm{Gyn}$ resident must master its management. This model can be implemented in several ways. A number of courses such as Managing Obstetrical Risk Efficiently (MORE-OB) and Advances in Labour and Risk Management (ALARM) have already integrated PPH into their curriculum and are being used by obstetrical health professionals all over Canada [15-16]. Some centers consolidate the knowledge gained in these courses through teambased simulation.

The uterine towel model for compression sutures can be added as part of the PPH module of these courses. This simulator can also be integrated into the $\mathrm{Ob} / \mathrm{Gyn}$ residency curriculum as a simple task trainer during protected teaching time. This was done last year with the McGill Ob/Gyn residents, but the tool was not evaluated and there was no associated assessment of the residents. The simulator can also be integrated into a hybrid PPH simulation scenario as part of a larger assessment for the management of PPH, involving the entire team. The latter has been done at the University of Ottawa in the past: a resident had to manage PPH after a vaginal delivery in a hybrid model with a standardized patient and pelvis. They had to demonstrate knowledge and the application of medical management of PPH. The scenario continued with the need for a Bakri balloon for tamponade, of which the placement was demonstrated. The patient continued to bleed, thus the need for surgical management was identified, and the different techniques including uterine compression sutures were stated. The resident then had to demonstrate the correct placement of uterine compression sutures on a similar towel model. An objective structured assessment of technical skills (OSAT)-style PPH assessment scenario for residents is described in the section below by Quinn et al. [14]. The key to learning the correct technique is feedback "in" or "on action" and deliberate practice, or "expertlevel" practice. Each resident can potentially have their own personal model to take home and practice on for self-learning until they are comfortable with the techniques. This low cost, mobile, feasible simulator can be used both as a formative or summative assessment of the residents' surgical skill in using uterine compression sutures.

\section{Assessment tool}

There are a number of studies that show the positive effects of simulated team-based obstetrical emergency drills, including those for PPH [17-18]. Furthermore, the MORE-OB Program, which includes didactic lessons, workshops, and in-hospital simulation drills on PPH, is being implemented in hospitals on a national level [15]. One study, which looked at teaching surgical management of PPH to residents on cadavers, showed positive results in terms of improved theoretical knowledge, technical skills, and self- 
confidence, based on pretest and post-test questionnaires [19]. Thus, this study did not rely on any predetermined assessment tools.

Only one article was found that evaluated a curriculum to teach and evaluate resident skills for both medical and surgical management of PPH. It describes a four-station OSAT, including a GRS and a task-specific checklist for the uterine compression suture station [14]. Instructions were provided to the residents in the form of a self-study packet and included procedural knowledge for the performance of various compression sutures. This particular study found an inter-rater reliability of 0.93 for the seven-point uterine suture taskspecific checklist (See Figure 9) and 0.77 for the GRS. Upon looking at the items on this checklist, it was found that some items are vague, such as "correctly performed the steps." These steps should be outlined in detail to differentiate the performance of different residents. The same GRS they used had been previously studied by Reznick et al. in the field of General Surgery [20]; thus, its validity in this particular Ob/Gyn setting is questionable as some of the items on the scale, such as tissue handling, cannot be adequately assessed on a plastic (or towel) model compared to a real uterus. The GRS can be found in Figure 10 . Construct validity was also determined to be significant and solely based on the fact that senior residents performed superiorly compared to junior residents on both the GRS $(p=0.006)$ and the checklist $(p=0.04)$. However, as will be mentioned in the discussion below, construct validity assessment has many more intricate levels. Based on a Likert scale, residents felt that this curriculum improved both their knowledge $(4.8 / 5)$ and their ability to perform uterine compression sutures (4.1/5). Moreover, a pre- and post-test showed a significant improvement of mean scores in knowledge. These outcomes measure Kirkpatrick levels 1 (Reaction) and 2 (Knowledge) [21]. No study up to date has looked at the outcomes of a similar PPH curriculum related to the performance of residents outside of simulation, in a real-world operating room, or at an even higher level, at patient outcomes (Kirkpatrick levels 3 and 4).

\footnotetext{
Yes No

1. Examiner correctly recognizes when there is a postpartum hemorrhage

2. Examiner identifies the risk factors for postpartum hemorrhage (both general and specific to the patient).

3. Examiner properly describes the physiologic classification of the hemorrhage.

4. Examiner lists the etiologies of postpartum hemorrhage.

5. Examiner appropriately calls for assistance.

6. Examiner correctly asks for IV lines and lab studies.

7. Examiner performs proper resuscitative efforts: asks for IV, sends proper labs, performs uterine massage, asks for correct uterotonic agents and doses (and knows their contraindications), gives oxygen, inserts foley.

8. Examiner correctly determines when patient needs exam under anesthesia or surgical intervention.
}

FIGURE 9: Task-specific checklist for uterine compression sutures [14]. 


\section{Cureus}

GLOBAL RATING SCALE OF OPERATIVE PERFORMANCE

Please circle the number corresponding to the candidate's performance in each category, irrespective of training level

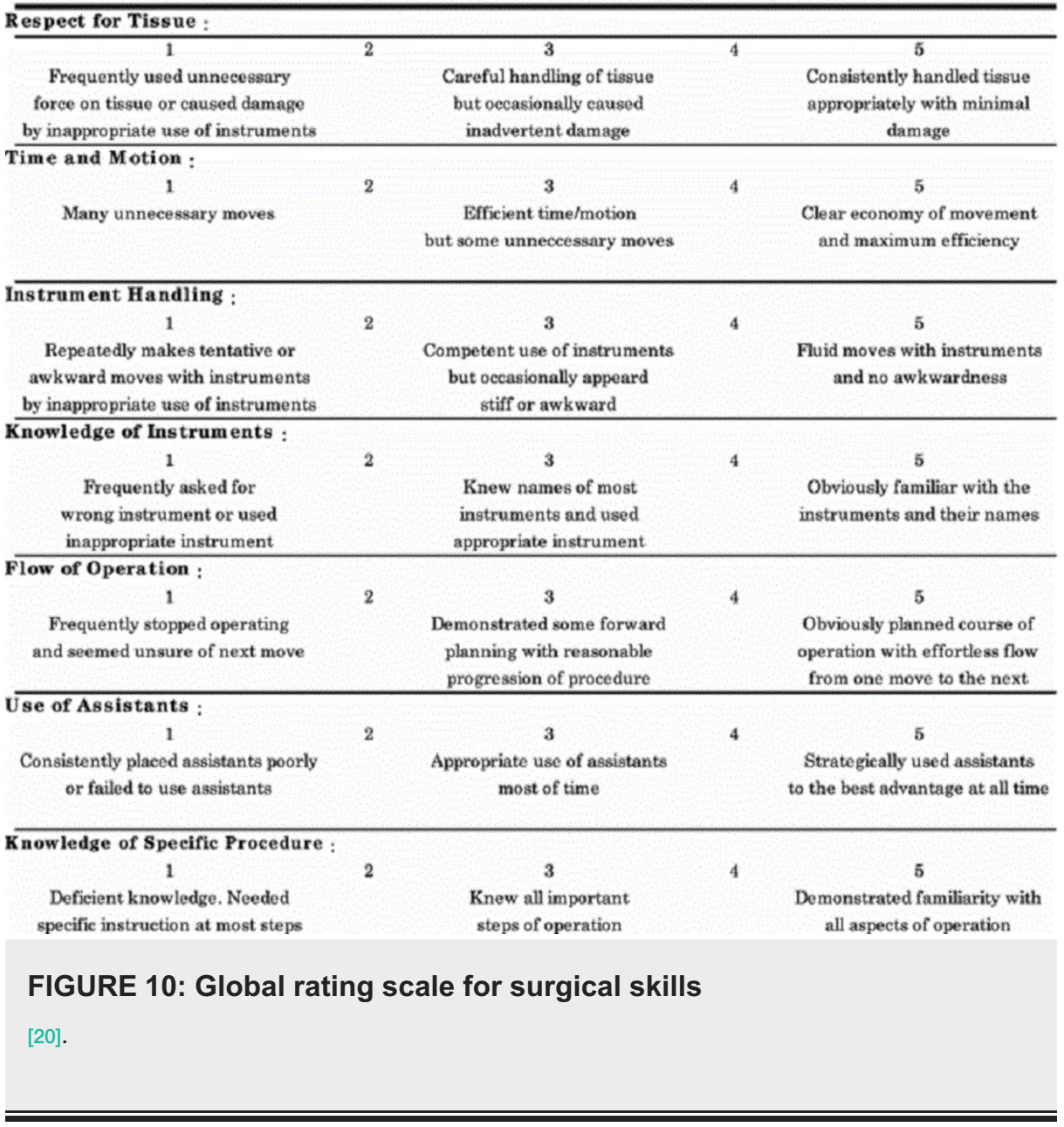

The rubric described in this article was developed for the formative performance-based assessment of BLynch, Hayman, and Cho compression sutures (See Tables 1-2). Ideally, a consensus group of experts or a Delphi survey could be used to design such a rubric; however, for our purposes, the rubric was designed using current literature and personal experience. Similarly, a GRS or a checklist could be used, such as the one described in the study above. In this case, due to the formative nature of the assessment, it was preferred to use a rubric based on the level of performance (Dreyfus levels of skills acquisition) in order to identify the resident's expected and observed level of performance for their learning and improvement. We did not use the predetermined checklist in Figure 9 because, as mentioned previously, it was felt to be too vague and the authors did not provide information on how this checklist was developed. 


\section{Cureus}

For this assessment, the trainee:

1. Recognizes when surgical management of postpartum hemorrhage (PPH) is needed.

- For uterine atony, after failed medical management or balloon tamponade

2. Knows the different options for surgical management of PPH, including the relevant anatomy.

- Uterine tamponade

- Uterine artery embolization (interventional radiology)

- Uterine compression sutures

- Uterine or internal iliac artery ligation

- Hysterectomy

3. Describes B-Lynch, Hayman, and Cho uterine compression sutures.

- What are the main differences between these techniques?

- If shown diagrams of each, can correctly them identify

4. Selects the appropriate suture/needle material and instruments for the compression suture.

- Monocryl or chromic no 1.0 or 2.0 suture (absorbable, monofilament); ideally NOT vicryl or PDS

- Either curved 70 mm (or larger) needle (B-Lynch) or straight \#7 or \#8 needle (Hayman/Cho)

5. Demonstrates B-Lynch, Hayman, and Cho uterine compression sutures on a uterine model.

- Clearly knows the steps and principles for each technique

- For B-Lynch/Hayman: entry/exit points are $3 \mathrm{~cm}$ above or below the hysterotomy incision and 3-4 cm from the lateral edge (to avoid uterine artery/ureter injury)

- For Cho: each "square" has 2-3 cm edges and, if in the lower uterine segment, is at least $3 \mathrm{~cm}$ from the lateral edge (to avoid uterine artery/ureter injury)

6. Performs the compression sutures in a timely and efficient manner.

TABLE 1: Rubric for performance-based assessment of B-Lynch, Hayman, and Cho uterine compression sutures - instructions for trainee 


\begin{tabular}{|c|c|c|c|}
\hline Name & Stage of Residency: & Date: & \\
\hline \multirow{2}{*}{ Criteria } & \multicolumn{3}{|l|}{ Performance levels } \\
\hline & Level 3 (Competent) & Level 2 (Advanced beginner) & Level 1 (Novice) \\
\hline $\begin{array}{l}\text { Recognizes the need for } \\
\text { surgical management of } \\
\text { uterine atony based on } \\
\text { the case presented. }\end{array}$ & $\begin{array}{l}\text { Recognizes the need for surgical } \\
\text { management, and can list all five } \\
\text { options (balloon tamponade, } \\
\text { embolization, internal iliac/uterine artery } \\
\text { ligation, uterine compression sutures, } \\
\text { and hysterectomy). }\end{array}$ & $\begin{array}{l}\text { Recognizes the need for surgical } \\
\text { management, but cannot list all } \\
\text { five options (balloon tamponade, } \\
\text { embolization, internal iliac/uterine } \\
\text { artery ligation, uterine compression } \\
\text { sutures, and hysterectomy). }\end{array}$ & $\begin{array}{l}\text { Recognizes that } \\
\text { medical management is } \\
\text { not working and the } \\
\text { need for something } \\
\text { different, but does not } \\
\text { know what the next } \\
\text { options are. }\end{array}$ \\
\hline $\begin{array}{l}\text { Describes the difference } \\
\text { between the B-Lynch, } \\
\text { Hayman, and Cho } \\
\text { compression suture } \\
\text { techniques and can } \\
\text { select the correct } \\
\text { depiction for each. }\end{array}$ & $\begin{array}{l}\text { Knows and explains the main } \\
\text { differences: the hysterotomy is open (B- } \\
\text { Lynch/Cho) or closed (Hayman/Cho) and } \\
\text { B-Lynch is the only one that does not go } \\
\text { through the anterior and posterior walls. } \\
\text { Correctly identifies each picture. }\end{array}$ & $\begin{array}{l}\text { Knows and explains the main } \\
\text { differences, but cannot say which } \\
\text { technique is which or does not } \\
\text { correctly identify each picture. }\end{array}$ & $\begin{array}{l}\text { Does not know the } \\
\text { differences, thus cannot } \\
\text { explain or identify the } \\
\text { pictures. }\end{array}$ \\
\hline $\begin{array}{l}\text { Selects the appropriate } \\
\text { suture material and } \\
\text { instruments for } \\
\text { compression suture. }\end{array}$ & $\begin{array}{l}\text { Selects the correct suture/needle and } \\
\text { instruments without hesitation. }\end{array}$ & $\begin{array}{l}\text { Hesitates with the types of suture } \\
\text { material and is uncertain about the } \\
\text { selection, but correctly selects the } \\
\text { suture/needle and instruments. }\end{array}$ & $\begin{array}{l}\text { Selects the wrong } \\
\text { suture/needle or } \\
\text { instrument. }\end{array}$ \\
\hline $\begin{array}{l}\text { Demonstrates the B- } \\
\text { Lynch compression } \\
\text { suture technique. }\end{array}$ & $\begin{array}{l}\text { Demonstrates the technique perfectly } \\
\text { without any errors. }\end{array}$ & $\begin{array}{l}\text { Most of the technique is done well, } \\
\text { but the sutures are not } 3 \mathrm{~cm} \text { above } \\
\text { and below the incision or not 3-4 } \\
\mathrm{cm} \text { from the lateral borders. }\end{array}$ & $\begin{array}{l}\text { Does not know how to } \\
\text { perform this } \\
\text { technique (multiple } \\
\text { errors). }\end{array}$ \\
\hline $\begin{array}{l}\text { Demonstrates the } \\
\text { Hayman compression } \\
\text { suture technique. }\end{array}$ & $\begin{array}{l}\text { Demonstrates the technique perfectly } \\
\text { without any errors. }\end{array}$ & $\begin{array}{l}\text { Most of the technique is done well, } \\
\text { but the sutures are not } 3-4 \mathrm{~cm} \text { from } \\
\text { the lateral borders. }\end{array}$ & $\begin{array}{l}\text { Does not know how to } \\
\text { perform this } \\
\text { technique (multiple } \\
\text { errors). }\end{array}$ \\
\hline $\begin{array}{l}\text { Demonstrates the Cho } \\
\text { compression suture } \\
\text { technique }\end{array}$ & $\begin{array}{l}\text { Demonstrates the technique perfectly } \\
\text { and safely without any errors. }\end{array}$ & $\begin{array}{l}\text { Most of the technique is done well, } \\
\text { but the suture points are either less } \\
\text { or more than } 2-3 \mathrm{~cm} \text { away from } \\
\text { each other, or too close to uterine } \\
\text { vessels. }\end{array}$ & $\begin{array}{l}\text { Does not know how to } \\
\text { perform this technique. } \\
\text { (Multiple errors). }\end{array}$ \\
\hline $\begin{array}{l}\text { Performs the sutures in a } \\
\text { timely and efficient } \\
\text { manner }\end{array}$ & $\begin{array}{l}\text { Completes the suturing tasks in criteria } \\
3,4,5 \text { within } 10 \text { minutes. }\end{array}$ & $\begin{array}{l}\text { Completes the suturing tasks in } \\
\text { criteria } 3,4,5 \text { in more than } 10 \\
\text { minutes. }\end{array}$ & $\begin{array}{l}\text { Is unable to complete } \\
\text { the task in the allotted } \\
\text { time. }\end{array}$ \\
\hline rall Level & c: & 3 & \\
\hline
\end{tabular}

TABLE 2: Rubric for performance-based assessment of B-Lynch, Hayman, and Cho uterine compression sutures - instructions for rater

The construct validity and reliability of this assessment tool have not yet been studied, but a description of possible ways to assess both these concepts will be elaborated. Validity refers to the concept that the test measures what it is supposed to measure (what do the results or scores actually mean?) and it is the single most important characteristic of assessment data [22]. Without validity, assessment data have little to no meaning. As the goal of this assessment tool is formative/lower-stakes, the amount of validity evidence is less than that required for higher-stakes exams. Downing provides us with a simplified interpretation of Messick's sources of test validity, which include five sources: content, response process, internal structure (includes reliability), relations to other variables, and evidence based on consequence of testing [22]. According to Downing, at least two different categories of validity evidence are required for most measures, more for higher-stakes exams. In terms of content evidence, there should be a relationship between the test content and the construct of interest. The tool's content relates to the learning objectives for $\mathrm{Ob} / \mathrm{Gyn}$ residency training, which is that: a fully trained resident must be competent to perform independently both "nonsurgical and surgical management of moderate and severe PPH", including the use of uterine compression sutures [3]. The specific content criteria are based on current medical knowledge [1-2] as well as 
the described procedure in the literature by the respective authors of each technique (B-Lynch, Hayman, and Cho) $[5,9,11]$, and my own personal expertise in the field of $\mathrm{Ob} / \mathrm{Gyn}$. The relationship to other variables can be assessed by comparing this new assessment tool with the checklist and GRS described in the article above as well as by discriminating between junior and senior learners (expert-novice performance comparisons). The consequences of the tool on the trainees can be assessed using a pre- and post-test questionnaire, aimed at evaluating whether the tool positively aided in their learning of the task, which is the main goal (e.g., using self-efficacy or confidence scores). Construct-irrelevant variance is a threat to validity for this specific tool and will need to be assessed. In order to decrease this threat, raters will need to be trained to use the tool in a systematic way and limit their biases. Each item in the rubric should be reviewed and deemed appropriate, in a process called item analysis (ideally as stated above by an expert group) to avoid construct under-representation, another threat to validity. The authors Quinn et al. do not explain how they came up with the items on their checklist. Adjustments to the criteria will be made if the expected level of performance is always under or over that observed. This can be done during pilot studies, before widespread implementation. Reliability is an integral part of internal structure validity and refers to the reproducibility of the data or scores of the assessment. The fewer random errors there are, the higher the reliability. The Cronbach's alpha can be used to measure internal consistency reliability. In this case, a score of 0.70-0.79 would be acceptable as it is a lower-stakes assessment.

Eventually, this performance-based assessment of uterine compression sutures for PPH can become part of a larger higher-stakes assessment for PPH as a whole. If this becomes the case, more validity and reliability evidence will be required. For example, and similar to the study described at length, it may be integrated as part of an OSAT on PPH which would comprise several stations, including a PPH drill with a standardized patient (possibly a hybrid model), a suturing station, and a Bakri balloon insertion station, amongst other possibilities. Reliability can be increased by combining this assessment score with others, leading to a composite score, as well as by item analysis, mentioned above. Inter-rater reliability also needs to be assessed to ensure reliability. This can be done using a number of statistical methods like the Pearson correlation coefficient. Training raters to use the assessment tool will not only help decrease constructirrelevant variance, as previously mentioned, but can also increase inter-rater reliability. Presently, the tool has only three levels of assessment, aligned with Dreyfus and Dreyfus' levels of skills acquisition one-three: novice, advanced beginner, and competent [23]. This may be expanded to a larger scale (e.g., five) if pilot studies show any threats to reliability or validity or if it is felt that level four (proficient) and five (expert) need to be defined.

\section{Conclusions}

Postpartum hemorrhage remains the leading cause of maternal mortality worldwide. A number of medical and surgical management techniques are available to prevent morbidity and mortality associated with PPH. Uterine compression sutures provide a more conservative surgical approach, allowing for the preservation of fertility. Ob/Gyn residents need to be adequately trained to competently perform this technique. A uterine towel model for surgical skills training in using uterine compression sutures was developed along with a performance-based assessment rubric in order to aid residents' learning and understanding of the technique. Much work is still needed to test the validity and reliability of this tool, but based on current literature, results may be promising.

\section{Additional Information \\ Disclosures}

Conflicts of interest: In compliance with the ICMJE uniform disclosure form, all authors declare the following: Payment/services info: All authors have declared that no financial support was received from any organization for the submitted work. Financial relationships: All authors have declared that they have no financial relationships at present or within the previous three years with any organizations that might have an interest in the submitted work. Other relationships: All authors have declared that there are no other relationships or activities that could appear to have influenced the submitted work.

\section{References}

1. Chapter 41: Obstetrical hemorrhage. Williams Obstetrics, 24th edition. Cunningham FG, Leveno KJ, Bloom SL, et al. (ed): McGraw Hill Education, New York; 2014. 780-828.

2. Leduc D, Senikas V, Lalonde AB, Clinical Practice Obstetrics Committee: Active management of the third stage of labour: prevention and treatment of postpartum hemorrhage. J Obstet Gynaecol Can. 2009, 31:980993. 10.1016/j.ijgo.2009.11.002

3. Royal College of Physicians and Surgeons of Canada: Objectives of training in the specialty of obstetrics and gynecology. 2016, Accessed: April 9, 2018: http://www.royalcollege.ca/cs/groups/public/documents/document/ltaw/mti0/ edisp/rcp-00124201.html.

4. B-Lynch C, Coker A, Lawal AH, Abu J, Cowen MJ: The B-Lynch surgical technique for the control of massive postpartum haemorrhage: an alternative to hysterectomy? Five cases reported. Br J Obstet Gynaecol. 1997, 104:372-375.

5. Cho JH, Jun HS, Lee CN: Hemostatic suturing technique for uterine bleeding during cesarean delivery . Obstet Gynecol. 2000, 96:129-131.

6. Hayman RG, Arulkumaran S, Steer PJ: Uterine compression sutures: surgical management of postpartum 
hemorrhage. Obstet Gynecol. 2002, 99:502-506.

7. Doumouchtsis SK, Papageorghiou AT, Arulkumaran S: Systematic review of conservative management of postpartum hemorrhage: what to do when medical treatment fails. Obstet Gynecol Surv. 2007, 62:540-547. 10.1097/01.ogx.0000271137.81361.93

8. Kayem G, Kurinczuk JJ, U. K. Obstetric Surveillance System: Uterine compression sutures for the management of severe postpartum hemorrhage. Obstet Gynecol. 2011, 117:14-20.

9. Mallappa Saroja CS, Nankani A, El-Hamamy E: Uterine compression sutures, an update: review of efficacy, safety and complications of B-Lynch suture and other uterine compression techniques for postpartum haemorrhage. Arch Gynecol Obstet. 2010, 281:581-588. 10.1007/s00404-009-1249-z

10. Matsubara S, Yano H, Ohkuchi A, Kuwata T, Usui R, Suzuki M: Uterine compression sutures for postpartum hemorrhage: an overview. Acta Obstet Gynecol Scand. 2013, 92:378-385. 10.1111/aogs.12077

11. B-Lynch C, Javaid TA: B-Lynch compression suture as an alternative to paripartum hysterectomy. In Approaches to Hysterectomy. Amarin Z (ed): INTECH, 2015:117-136. 10.5772/61295

12. Pereira N, Delvadia D: A tool for teaching the B-Lynch brace suture method: an inexpensive new simulator allows obstetricians to polish an essential technique. Am J Obstet Gynecol. 2013, 209:591.

10.1016/j.ajog.2013.08.010

13. Houlihan S: B-Lynch suture for face cloth uterus . (2014). Accessed: April 9, 2018: http://rubberuterus.blogspot.ca/2014/09/b-lynch-suture-for-face-cloth-uterus.html?m=1 .

14. Quinn KH, Mackey A, Cohen J, Smith SJ: A curriculum to teach and evaluate resident skills in the management of postpartum hemorrhage. J Perinat Med. 2012, 40:635-639. 10.1515/jpm-2012-0072

15. Tetrault JM, Green ML, Martino S, et al.: Developing and implementing a multispecialty graduate medical education curriculum on Screening, Brief Intervention, and Referral to Treatment (SBIRT). Subst Abuse. 2012, 33:168-181. 10.1080/08897077.2011.640220

16. Walker DM, Cohen SR, Fritz J, et al.: Impact evaluation of PRONTO Mexico: a simulation-based program in obstetric and neonatal emergencies and team training. Simul Healthc J Soc Med Simul. 2016, 11:1-9. 10.1097/SIH.0000000000000106

17. Draycott T, Sibanda T, Owen L, et al.: Does training in obstetric emergencies improve neonatal outcome? BJOG. 2006, 113:177-182. 10.1111/j.1471-0528.2006.00800.x

18. Fransen AF, van de Ven J, Schuit E, van Tetering A, Mol BW, Oei SG: Simulation-based team training for multi-professional obstetric care teams to improve patient outcome: a multicentre, cluster randomised controlled trial. Br J Obstet Gynaec. 2016, 641-650. 10.1111/1471-0528.14369

19. Kerbage Y, Debarge V, Lucot JP, Clouqueur E, Rubod C: Simulation training to teach postpartum hemorrhage surgery to residents. Eur J Obstet Gynecol Reprod Biol. 2016, 201:27-30. 10.1016/j.ejogrb.2016.03.013

20. Reznick R, Regehr G, MacRae H, Martin J, McCulloch W: Testing technical skill via an innovative "bench station" examination. Am J Surg. 1997, 173:226-230.

21. Kirkpatrick DL, Kirkpatrick JD: Evaluating Training Programs: The Four Levels, 3rd Edition . Berrett-Koehler Publishers, Inc., San Francisco, CA; 2006.

22. Assessment in Health Professions Education. Downing SM, Yudkowsky R (ed): Taylor and Francis Group, New York; 2009.

23. A five-stage model of the mental activities involved in directed skill acquisition . 1980, Accessed: April 9, 2018: http://www.dtic.mil/dtic/tr/fulltext/u2/a084551.pdf. 